\title{
AN ATTEMPT TO USE SONIC TESTING IN CASTING QUALITY ASSESSMENT
}

\begin{abstract}
Andrzej Białobrzeski
S u m m a r y

The aim of the present study has been designing and putting in operation of a stand for Sonic Testing equipped with modern and readily available digital devices and with the author's own computer program, which enables recording and analysis of acoustic fields and of the frequency of free vibrations in selected castings made from $\mathrm{Fe}$ and Al alloys, and specifically also from magnesium alloys, and mastering the technique of making such tests along with their practical application in assessment of the quality of castings made from magnesium alloys and investment castings made from carbon steel.

Keywords: Non-Destructive Testing, Sonic Testing
\end{abstract}

\section{Próba zastosowania metody badań dźwiękowych (Sonic Testing) do oceny jakości odlewów}

$$
\text { Streszczenie }
$$

W referacie przedstawiono opracowane stanowisko badań dźwiękowych odlewów. W budowie stanowiska stosowano nowoczesne urządzenia cyfrowe. Wprowadzono autorskie oprogramowanie, umożliwiające zapis i analizę pola akustycznego oraz częstotliwości drgań odlewów. Do badań weryfikacyjnych przyjęto odlewy ze stali oraz stopów aluminium i magnezu.

Słowa kluczowe: badania nieniszczące, badania dźwiękowe (Sonic Testing)

\section{Introduction}

Application of acoustic phenomena, i.e. of vibrations at frequency lying within an audible range of $20-20000 \mathrm{~Hz}$, in assessment of the metal parts quality and degree of wear is by no means a new idea. Some time ago it was used (and probably is still used occasionally nowadays) by the railway industry. When the train was standing on the station, a local "railway man" was walking slowly along the cars and tapping with a small hammer the axles and wheels listening carefully to the sound they produced. If the sound was high and clear it meant that the axles and wheels were not damaged; the sound dull and fading quickly indicated cracks or other damages in the axle or wheel. For this "sonic testing" Address: Prof. Andrzej BIAŁOBRZESKI, University of Bielsko-Biała, Department of
Manufacturing Technology and Automation, 43-309 Bielsko-Biała, Willowa 2,
Poland, phone: $(0-48,33) 8279$ 241, e-mail: abialobrzeski@iodl.krakow.pl 
of the elements of railway cars the workers should have a "good ear for music" and probably that was the reason why railway bands enjoyed popularity so great.

The natural frequency of an element (i.e. the frequency of vibrations lying within an audible range of 20-20 $000 \mathrm{~Hz}$ ) depends on a number of different factors, like factors of shape, i.e. the geometrical configuration of a part and the degree of its shape intricacy, the size and weight, wall thickness, etc., and factors related to the physical constants of material, e.g. modulus of elasticity, density, etc., which are determined by the texture and structure of material. This means that:

\section{The natural frequency of an element $=F$ (shape factors, material factors)}

The above formula indicates that if the shape factors of some elements remain constant, the frequency of free vibrations of an element may serve as an indication of its quality, specially when related to the physical constants of this material, like the content of some structural constituents characterised by the acoustic properties other than those of the matrix, e.g. the type and shape of graphite precipitates in cast iron, the precipitates of silicon in aluminium alloys, or the discontinuities of material in the form of various defects, cracks, etc.

In solid media which are characterised by some elasticity of both volume and shape, it is possible to have the propagation of both longitudinal as well as transverse waves and of the waves which are a combination of the two aforementioned types, e.g. Reyleigh surface waves and Lamb plate waves. In unbound model systems, only the longitudinal and transverse waves can propagate. In media bound by one surface only, in which the wave length is larger than the size of the medium, the propagation of surface waves takes place. On the other hand, in media bound by two parallel surfaces (e.g. plates, coatings) the Lamb plate waves are propagating. Since, in the majority of cases, castings form systems differing considerably from the model ones (e.g. a plate or a cylinder), and are usually characterised by a high degree of surface development, the frequency of their free vibrations is a resultant of these waves present in different proportions and determined in each individual case from the specific casting configuration.

When sound waves are propagating in anisotropic media, which all technical alloys certainly are, and the medium has some discontinuities (porosities, cracks, etc.), the distribution of acoustic field will suffer a distortion, if within this medium there is an obstacle of dimensions equivalent to the wave length. By obstacle we understand a closed area of acoustic properties other than the properties of the medium (e.g. density, elasticity, etc.). On a phase boundary of this obstacle, the effect of the wave reflection, diffraction and scattering occurs. Therefore the obstacle is to be regarded as a source of the wave 
disturbances which by superimposing on the acoustic field determine the frequency of the free vibrations of an object.

The decay of acoustic field - the wave attenuation in solid media - is caused by an imperfect elasticity of the medium, by thermoplastic effects, elastic hysteresis, dislocation phenomena, etc. There is also the effect of wave scattering induced by a polycrystalline alloy structure, known as Reyleigh scattering.

To prevent the decay of vibrations, it is necessary to supply them continuously with some energy in the form of external impulses. The impulses cause changes in the amplitude and phase of free vibrations and generate vibrations of frequency $f$ superimposing on the element (casting) free vibrations of frequency $f_{0}$. Then, the amplitude of the resultant vibrations of the element will depend on the frequency $f$ and will reach its maximum when:

$$
f^{2}=f_{0}^{2}-2 \beta^{2}
$$

where: $f-$ is the frequency of forced vibrations, $\beta$ - is the coefficient of attenuation (the decrement of wave attenuation).

The occurrence of a maximum is a result of the resonance, while the frequency at which it occurs is called resonance frequency of the free vibrations of an element. With any arbitrary forced frequencies, the free vibrations of an element become stable when the amount of energy lost on account of internal friction is equal to the amount of energy supplied by forced vibrations.

So, the method of sonic (acoustic) testing will consist either in measurement of the frequency of free vibrations of an element (casting) or in measurement of the time of the vibrations decay after their excitation, i.e. in measurement of the damping capacity. The obtained value of the first resonance frequency equal to the frequency of free vibrations, or the time of vibration damping in the tested casting (element) are compared with the frequency of free vibrations or with the damping time of a reference casting (element) satisfying all requirements of the technical acceptance conditions (TAC).

The non-destructive techniques of the casting quality inspection can be classified according to different criteria [1]. These can be, for example, the methods of surface inspection, like magnetic flaw detection, the use of various penetrants, visual inspection, etc. The second group are the volumetric methods, i.e. radiography and thermography, acoustic emission, ultrasonic tests, etc.

The method of sonic (acoustic) testing is included in the second group of non-destructive tests. By this method an overall casting quality is evaluated in terms of both structural properties (e.g. the degree of graphite spheroidisation, the results of austempering) as well as the discontinuities present in the examined material (casting defects, cracks, etc.). The method can be used in 
a widely understood assessment of casting quality and is applicable to castings of both simple as well as intricate shapes. It can be expected that this method will find its application in all these cases when it is necessary to examine in a relatively short time the quality of a batch of castings under the strictly determined conditions of technical acceptance.

It should be stressed that, basically speaking, sonic tests do not define the type of defect (flaws in structure, misconfiguration of casting, breaks in material continuity, etc.); they only enable stating that the casting does not comply with the technical acceptance conditions (TAC). Nevertheless, due to its simplicity, easy application and rather modest (at present) outlays necessary for organisation of a test stand, this technique of testing is expected to become a tool of choice for the industrial practice [2-8].

The aim of the exploratory research was assessment of the possibility to use in evaluation of the casting quality either a decrement of the free vibration damping or the frequency of free vibrations (the resonance frequency) of an object. Another task was assessment of the sensitivity of these methods and of their applicability in identification of structure quality (e.g. the degree of cast iron spheroidisation) and/or of the discontinuities (e.g. porosities, cracks, etc.) in castings made from $\mathrm{Fe}, \mathrm{Al}$ and $\mathrm{Mg}$ alloys.

\section{Research methodology}

Experts in acoustics have been consulted to recommend the best standard equipment for a stand used in sonic testing of castings. Applying in practice the obtained guidelines, an attempt has been made at designing a stand for sonic testing of castings utilising a modified version of one of the new computers available at the Foundry Research Institute in Kraków (an indispensable condition is the use of a Pentium P4 microprocessor built-in into the main board of computer, and installation of the following elements: professional sound card, directional microphone, filters, and signal amplifier). Additionally, a special author's program for visualisation and analysis of the acoustic fields has been developed. Its task is to compare the frequency of free vibrations of a standard reference casting (conformant with TAC) with the frequency of free vibrations of the tested casting. A solution has been proposed as regards the technique of supporting the castings selected for tests and the technique of a mechanical and repeatable inscitation of the sound waves in castings [6].

Figure 1 shows the overview of measuring instruments and the examined casting. However, Figure 2 - the acoustic measurement section and a placed in position 2-ribb casting. 


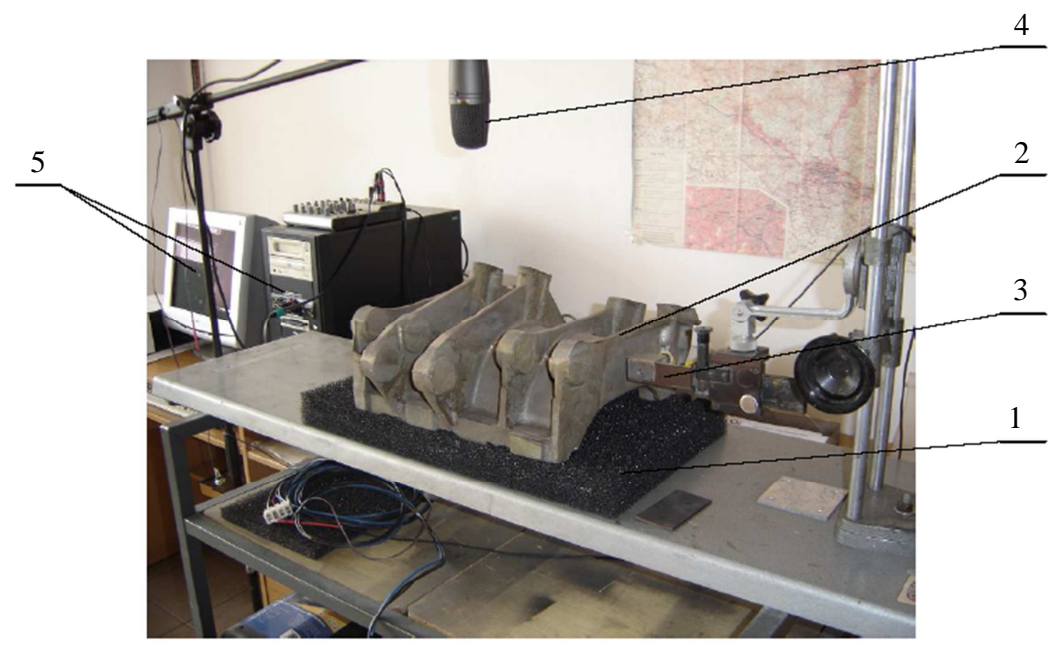

Fig. 1. General view of the test bed: 1 - measuring bench, 2 - five-rib casting from MgZA-7 magnesium alloy, 3 - device to mechanical excitation of vibrations, 4 - directional microphone to recording of acoustic field, 5 - computer with monitor to registration of sound from mixer connected to the microphone

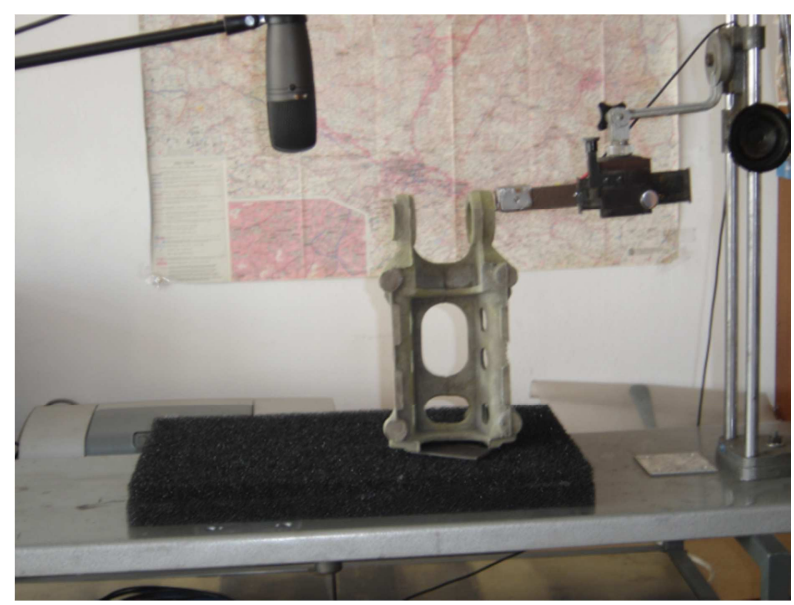

Fig. 2. The technique of fixing a 2-rib casting (the selected spot where vibrations are induced in the casting)

\section{Research results and their analysis}

The successive figures show, as an example, the pieces of information that are displayed on the computer monitor from a professional "Cool Edit Pro 2.0" program adapted specially to this purpose. 
When a microphone is used in recording of the acoustic field of casting vibrations, the main problem is evaluation of the level of "noise" coming from the environment and of its impact on the measurement. Therefore, at the beginning of the measurements, it was necessary to determine the level of acoustic interference in the compartment where the measurements were taken. For reasons quite obvious the level of interference was changing in time (the measurements were not taken in a silenced chamber), but attempts were made to take these measurements under repeatable acoustic conditions.

Figure 3 shows example of changes in the level of acoustic interference in a compartment where the measurements have been taken.

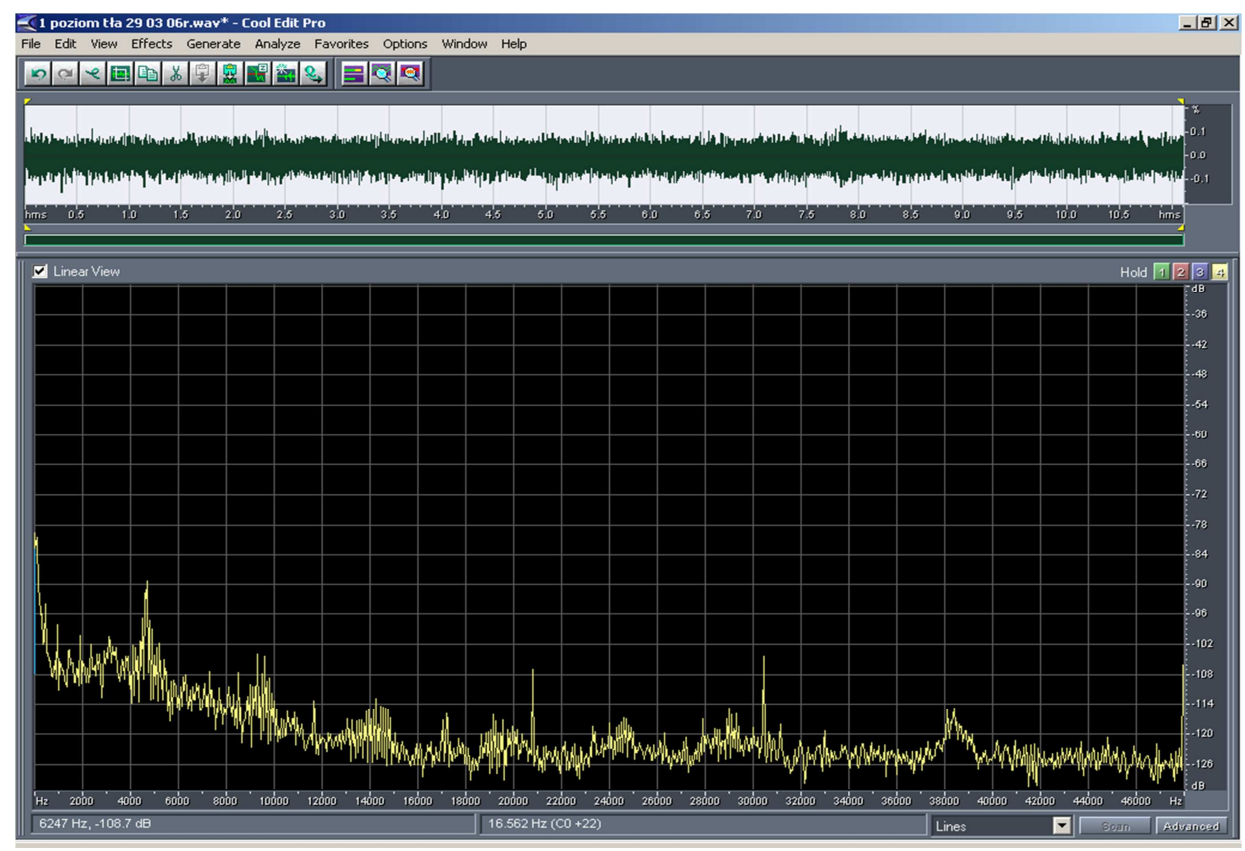

Fig. 3. Example of measurement of the level of acoustic interference

Figure 4 shows the example of superposition of the frequencies of free vibrations coming from five investment carbon steel castings with defects. The differences in acoustic fields of these castings are very clearly visible.

Figure 5 shows the example of superposition of the frequencies of free vibrations coming from two investment castings which, basing on the results of other tests, have been considered free from defects, and from three castings with defects. 


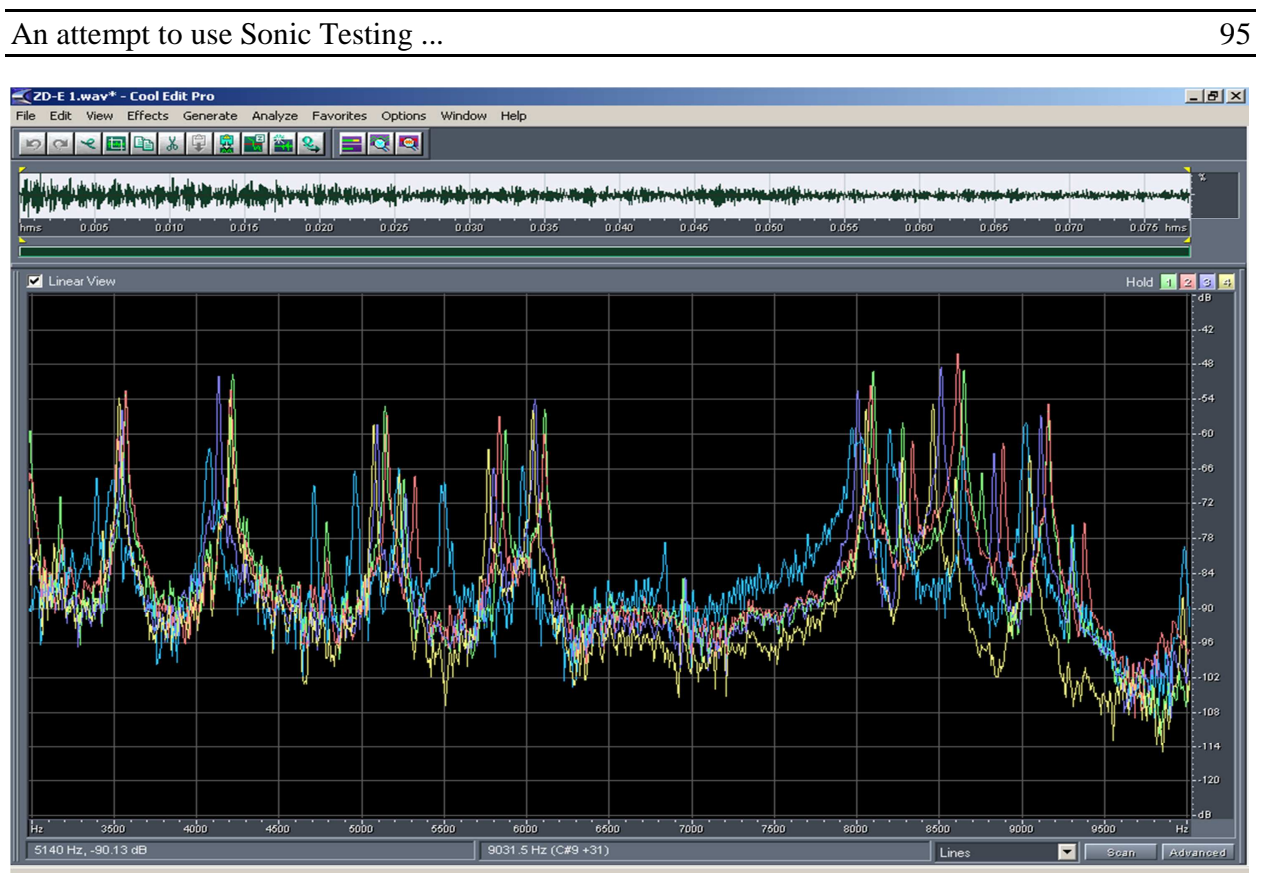

Fig. 4. Example of superposition of the plotted free vibrations of carbon steel castings with defects

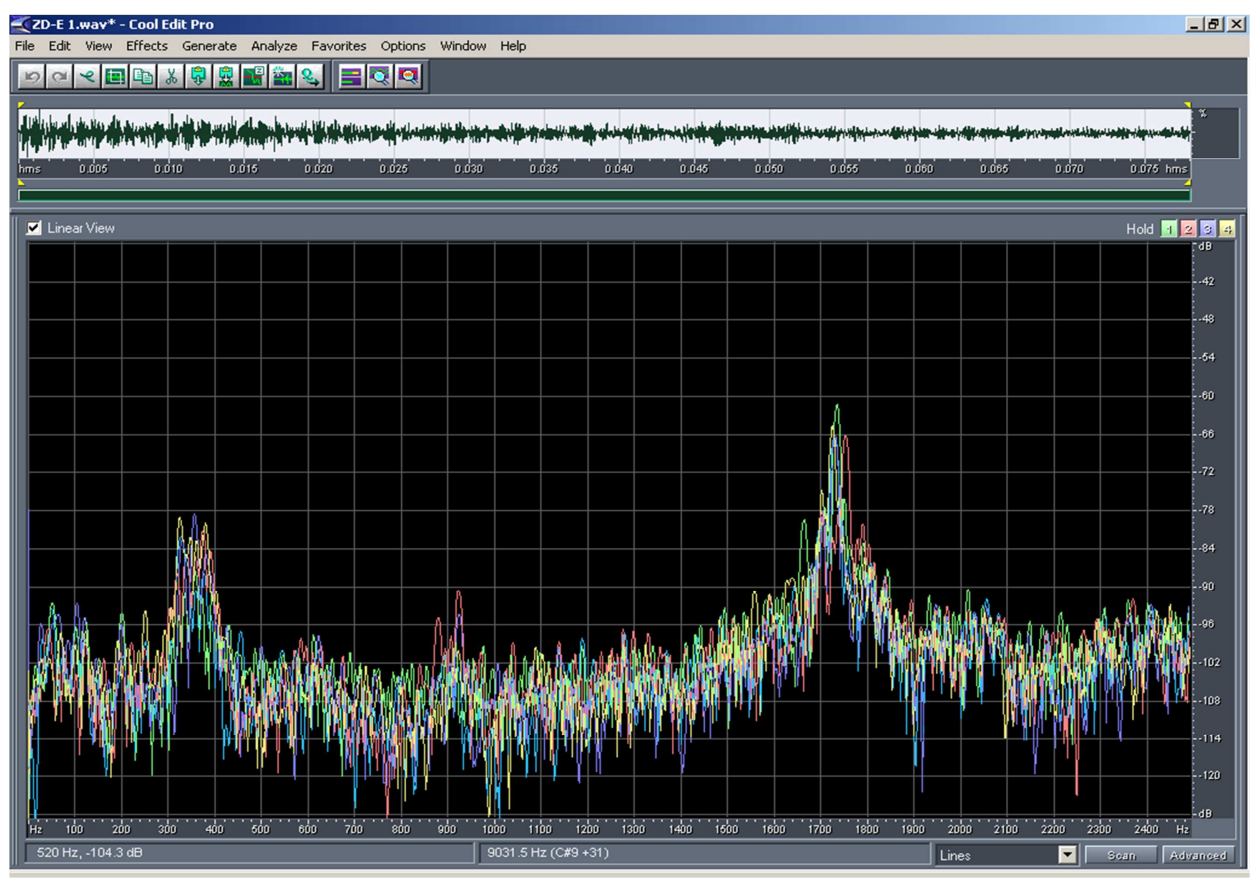

Fig. 5. Exemplary, superimposed diagrams of free vibrations course of cast carbon steel castings produced by investment casting process: on base of the tests two castings we assessed as correct, while three castings as defective 
Figure 6 shows the example of superposition of the frequencies of free vibrations coming from five carbon steel castings free from defects. The superposition of acoustic fields of these castings is characterized by a very high degree of accuracy which proves both good shape reproducibility as well as a very similar internal structure of these castings.

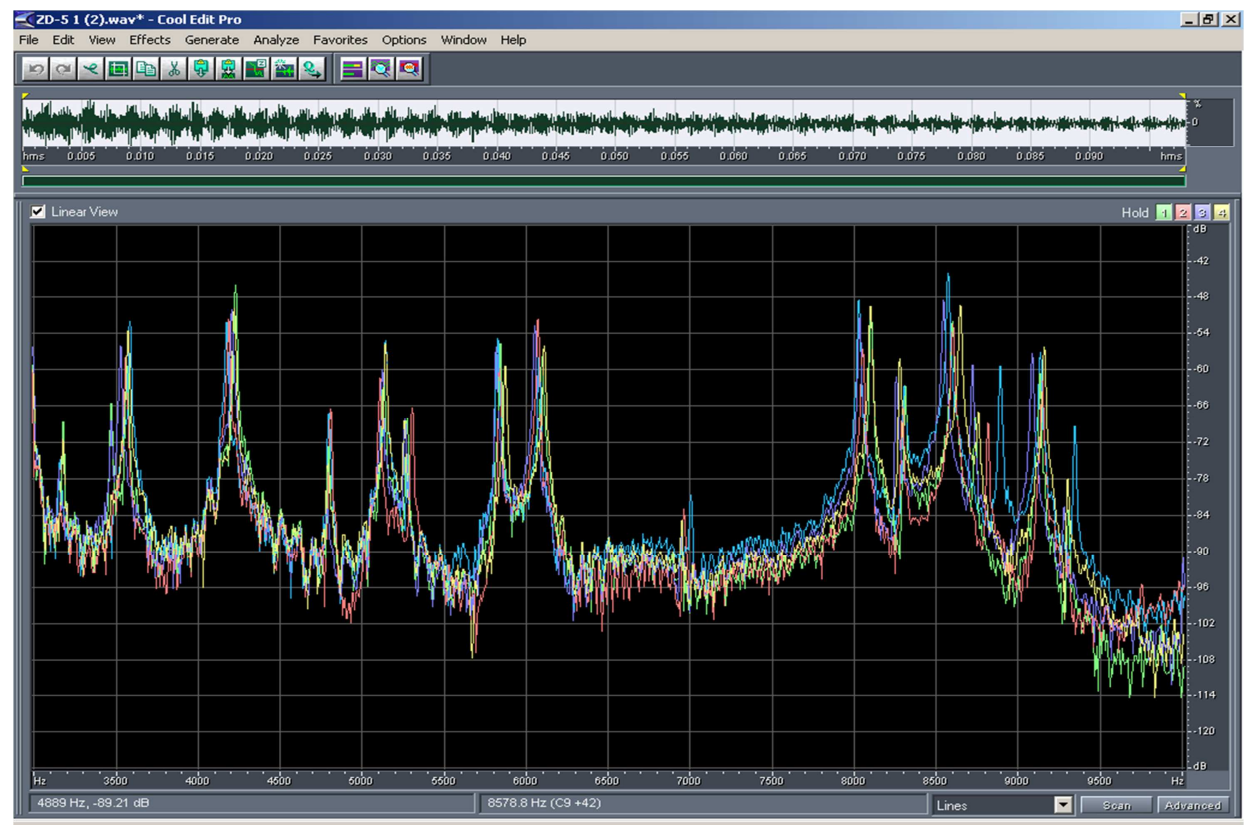

Fig. 6. Example of superposition of acoustic fields from defect-free castings

The above presented results of the measurements of acoustic fields of castings are but only a small fragment (the question of reprography) of the vast program of measurements carried out on various castings. The anaysis and interpretation of the obtained results of measurements is complicated, mainly on account of the two principal reasons.

First - the shape of real castings is basically different from the shape of model elements (perfect cylinder, plate, etc.). The acoustic fields (the frequency of free vibrations) of these model shapes are very simple with unambiguously determined places where the nodes of vibrations are present. Due to this, it is very easy to determine the places where the elements should be supported during measurements (these should be exactly the places where the nodes of vibrations are present). There is, moreover, a limited number of the unambiguously determined harmonic vibrations. In the case of developed structures - which castings usually are - the acoustic fields are very complicated with a large 
number of the superimposing harmonic vibrations, as visible in the plotted graphs of acoustic fields in castings. During analysis of the plotted graphs, the task is to find out and determine a basic frequency of the free vibrations of each casting. To do this, the potentials of a computer system are effectively utilised, but with the program available now this task is both difficult and timeconsuming.

Second - the computer program used currently for picking up and visualisation of acoustic fields is a professional program used by acoustic engineers to test e.g. the sound amplification in concert halls, and to the needs of the present measurements it has been only very roughly adapted. Therefore its operation is rather complicated, and the analysis of the frequency of free vibrations of castings requires additional operations related to, among others, filtering of "noise" coming from the acoustic background.

To make acoustic examinations - as a rapid, non-invasive and nondestructive test - applicable in industrial practice, it is necessary to use in measurements of the casting free vibrations, and possibly also in measurements of the decrement of vibration damping, not a microphone but a laser technique effectively eliminating the interference coming from the background (the stand for tests should be located on a production line - by nature generating a lot of noise); it is also necessary to develop a specialistic computer program for analysis of the field of vibrations and for consistent determination of the frequency of free vibrations.

The preliminary results of the measurements show us that, using a technique of the excitation of vibrations, picking them up and analysis, it is possible to state differences in the frequency of free vibrations of castings. This creates potential possibilities for drawing a relationship between this frequency and casting quality as determined by the technical acceptance conditions (TAC). The conducted preliminary investigations create a firm background for further attempts to apply the sonic testing in assessment of casting quality under production conditions.

\section{Conclusion}

It is necessary to detemine the range of frequencies of the casting free vibrations and, basing on the results of this analysis, repeat the test for a selected frequency which will cover only castings free from defects.

It is necessary to test each time whether castings are supported correctly during sonic testing.

The properly processed results of investigations should enable development of a computer program which will offer analysis of the plotted graphs of vibrations with calculation of the most important parameters and segregation of castings based on the results of conducted tests. 
An analysis of the results of investigations disclosed in this study consists in comparing the obtained values of the first resonance frequency with the frequency of free vibrations, or with the time of vibration damping in a standard reference casting satisfying all requirements of the technical acceptance conditions (TAC).

The method of sonic testing enables an overall assessment of the casting quality in respect of both structural properties (composition, graphite spheroidisation degree) as well as discontinuities present in material (casting defects, cracks, etc.).

The method can be used equally well in assessment of the widely understood casting quality in elements small and of large overall dimensions and of configurations both simple and intricate.

Acoustic testing does not, in principle, define the type of defect; it only enables stating if the casting satisfies or not the technical acceptance conditions.

It is expected that this method will find application in all those cases when it is necessary to know in a relatively short period of time the quality of a batch of castings with strictly determined conditions of technical acceptance.

In view of its simplicity, easy application and relatively modest (at present) finacial outlays necessary for designing and making a stand for tests, sonic testing has a good chance to be placed among the techniques used in industrial practice.

\section{References}

[1] I. HERTLIN: Acoustic resonance testing technology. Cast Metal, (2004)2-3, 21-22.

[2] T. MOROOKA, L. SUGUIJAMA: Effects of microsrtucture and residual stress on the sonic properties of gray cast iron. Modern Casting, (1969)3.

[3] A.G. FULLER: Assessment of casting quality by the measurement of resonat frequensy. Foundry Trade Journal, 115(1963).

[4] E. PLENARD: Relations entre la capacite d'amortissement, la structure et diverses propreite's mecaniques des fonts. Fonderia, 201(1962).

[5] A. BIAŁOBRZESKI, K STENCEL: Opracowanie automatycznej kontroli odlewów żeliwnych metodą badań dźwiękowych. Praca dyplomowa, Wydział Odlewnictwa AGH, Kraków 1969.

[6] A. BIAŁOBRZESKI, M. ORLIŃSKI, T. GROCHAL: Zastosowanie badań dźwiękowych (Sonic Testing) do oceny jakości odlewów. Archiwum Odlewnictwa, 6(2006) 18, 337-342.

[7] J. SZOPA, A. BIAŁOBRZESKI, K. STENCEL: Badania technologicznych możliwości zastosowania metod akustycznych do zautomatyzowanej nieniszczącej kontroli jakości odlewów żeliwnych. Zeszyty Naukowe AGH, 39, Kraków 1971.

[8] L.N. MOSKALOVA, V.A. MURAV'EV: Structure and acoustic properties of alloyed cast irons. Metal Science and Heat Treatment, 26(1984)11, 842-844. 